\title{
Labyrinthe
}

$7 \mid 2000$

Numéro 7

\section{Colloque " Au théâtre, au cinéma : au féminin »}

Colloque organisé par Paris-VIII et le Collège international de philosophie (21 et 22 janvier 2000 à l'Université Paris VIII-VincennesSaint-Denis et à l'École normale supérieure).

\section{Laurent Dubreuil}

\section{OpenEdition}

\section{Journals}

Édition électronique

URL : http://journals.openedition.org/labyrinthe/727

DOI : $10.4000 /$ labyrinthe.727

ISSN : 1950-6031

Éditeur

Hermann

Édition imprimée

Date de publication : 30 octobre 2000

Pagination : 169-171

Référence électronique

Laurent Dubreuil, «Colloque « Au théâtre, au cinéma : au féminin » », Labyrinthe [En ligne], 7 | 2000, mis en ligne le 20 avril 2005, consulté le 01 mai 2019. URL : http://journals.openedition.org/labyrinthe/727 ; DOI : 10.4000/labyrinthe.727

Ce document a été généré automatiquement le 1 mai 2019.

Propriété intellectuelle 


\title{
Colloque «Au théâtre, au cinéma : au féminin »
}

\author{
Colloque organisé par Paris-VIII et le Collège international de \\ philosophie (21 et 22 janvier 2000 à l'Université Paris VIII-Vincennes- \\ Saint-Denis et à l'École normale supérieure).
}

\section{Laurent Dubreuil}

1 Le Centre d'études féminines de l'Université de Paris-VIII est le seul lieu institutionnel doté d'une équipe doctorale qui propose de réfléchir aux problématiques de la différence sexuelle, et des différences en général. Les études féminines ont récemment organisé, sous la direction de Mireille Calle-Gruber, un colloque sur les rapports du théâtre et du cinéma avec le féminin. Ce fut l'occasion d'entendre des chercheurs et professeurs de diverses nationalités (en plus des universités françaises, celles de Cassino ou de Georgetown à Washington), des textes relevant de plusieurs disciplines et d'approches variées : théâtrologie, analyse filmique, histoire littéraire, herméneutique philosophique, sociologie de l'art. C'était aussi, et peut-être surtout, le moment d'une confrontation et d'une discussion avec les "gens de l'art ", dramaturge et metteurs en scène : Hélène Cixous, Ariane Mnouchkine, Daniel Mesguich.

2 À défaut de dessiner une grande orientation centrale, certaines lignes de force peuvent se dégager de cette multiplicité. On distinguerait ainsi un groupe de réflexions sur la création et la féminité, une sorte d'étude de cas et une interrogation plus théorique.

3 Le premier ensemble, le plus fourni, s'est intéressé de près aux définitions des identités sexuelles et au devenir-femme. Travaillant sur Freaks de T. Browning, Pascale Risterrucci a analysé les perturbations introduites dans toute conception fixiste par l'intervention de vrais «monstres", acteurs du film. En particulier, la mutilation par les monstres de la belle, «normale» et perfide Cléopâtre, peut être vue comme un massacre du corps hollywoodien starisé. Le film déconstruit le stéréotype féminin, de même que le travestissement des actrices en hommes qu'a évoqué Laura Mariani. Les exemples de Sarah Bernhardt et de Colette mettent l'accent sur une recherche de « l'insexué » à partir d'un déplacement de l'apparaître. 
Dans une autre optique, on s'est également interrogé sur l'accession des femmes à la création théâtrale et cinématographique. À l'époque moderne, au sein de la commedia dell'arte, Isabella Andreini fut la première diva, une divine comédienne articulant une carrière glorieuse de chef de troupe et une vie de mère conforme, comme l'a montré l'exposé de Françoise Decroisettes. Béatrice Didier s'est penchée sur l'œuvre dramatique de Madame de Staël longtemps négligée et sur la figure récurrente de Sapho, devenue une héroïne romantisée de l'improvisation inspirée. Plus tard, si l'on suit Geneviève Sellier, les films d'Agnès Varda et la collaboration Duras-Resnais, répondent à l'émergence du sujet cinématographique masculin de la « Nouvelle vague » liée aux Cahiers du cinéma. Cléo de cinq à sept, de Varda, dépouille la protagoniste d'une " féminité de mascarade "; Hiroshima mon amour renvoie au scandale des «tondues». En d'autres termes, comment une femme peut-elle s'imposer au cinéma ? et quels langages utilise-t-elle ? Les films d'Assia Djebar relèvent le défi d'une poétique au féminin dans la société algérienne. Ce qu'a commenté Mireille Calle-Gruber, qui a fait ressortir le lien entre la scène de Djebar et le théâtre antique.

5 Parallèlement, le dernier spectacle du Théâtre du Soleil, Tambours sur la digue, sous forme de pièce ancienne jouée par des marionnettes, a servi de référence continue, de paradigme d'un théâtre au féminin, considéré aux moments de l'écriture (avec Hélène Cixous), de la mise en scène (avec Ariane Mnouchkine) et de la réception-interprétation (avec Laurent Dubreuil). Hélène Cixous a expliqué l'immense travail de simplification et de soustraction que les marionnettes ont fait subir à la textualité. Au final, «tout tient à un fil», et les mots, et les scènes : la réalité étale de la marionnette rappelle alors la figure de Dame Gigogne. Précisément, le metteur en scène, alias le chef de troupe, est revenue, quant à elle, sur l'accouchement d'un spectacle impossible où les acteurs jouent les marionnettes. Par quels chemins il a fallu passer, les voies de la restriction et du dépouillement. Sur la piste de ce retrait, l'herméneute a étudié la défalcation du réel dans le texte de la pièce, où s'élabore une pensée du rien comme chose et qui se fonde sur les textes orientaux et les traditions du Déluge.

6 Ces réflexions ont formé un cœur vivant pour une théorie pratique du théâtre mis au féminin. Roger Bensky, dans une fiction théorique, a refondé le mythe de la naissance du dieu tutélaire du théâtre, Dionysos, sorti de la cuisse de Zeus. Le motif de cette «matrice du père " peut servir à comprendre le fonctionnement de la mise en scène. Dans cet art qu'il pratique avec une telle acuité, Daniel Mesguich a élucidé ses relations avec Électre et Médée, qu'il vient de montrer dans les textes de Sophocle et Euripide. Loin de toute misogynie prétendue, le texte euripidien dispose la femme sage et savante en face de l'homme philosophe. En ce sens, la pensée du théâtre, loin du savoir organisé et des institutions de la connaissance, se risque toujours au féminin.

7 Au total, ce colloque ne s'est pas contenté des stéréotypes sur la question du féminin, ni dans le sens du "phal(logo) centrisme", ni dans la veine d'un naturalisme de la différence des sexes. Cette déconstruction en acte de la notion a permis un retour sur le théâtre et sur le cinéma dans leur ensemble, du point de vue de leur exercice concret et de l'interprétation. 